\title{
High-resolution spectral information enables phenotyping of leaf epicuticular wax in wheat

Fátima Camarillo-Castillo ${ }^{*}$ (D) Trevis D. Huggins ${ }^{2}$, Suchismita Mondal', Matthew P. Reynolds ${ }^{1}$, Michael Tilley ${ }^{3}$ and Dirk B. Hays ${ }^{4}$

\begin{abstract}
Background: Epicuticular wax (EW) is the first line of defense in plants for protection against biotic and abiotic factors in the environment. In wheat, EW is associated with resilience to heat and drought stress, however, the current limitations on phenotyping EW restrict the integration of this secondary trait into wheat breeding pipelines. In this study we evaluated the use of light reflectance as a proxy for EW load and developed an efficient indirect method for the selection of genotypes with high EW density.

Results: Cuticular waxes affect the light that is reflected, absorbed and transmitted by plants. The narrow spectral regions statistically associated with EW overlap with bands linked to photosynthetic radiation $(500 \mathrm{~nm})$, carotenoid absorbance $(400 \mathrm{~nm})$ and water content $(\sim 900 \mathrm{~nm})$ in plants. The narrow spectral indices developed predicted $65 \%$ (EWI-13) and 44\% (EWI-1) of the variation in this trait utilizing single-leaf reflectance. However, the normalized difference indices EWI-4 and EWI-9 improved the phenotyping efficiency with canopy reflectance across all field experimental trials. Indirect selection for EW with EWI-4 and EWI-9 led to a selection efficiency of 70\% compared to phenotyping with the chemical method. The regression model EWM-7 integrated eight narrow wavelengths and accurately predicted $71 \%$ of the variation in the EW load $\left(\mathrm{mg} \cdot \mathrm{dm}^{-2}\right)$ with leaf reflectance, but under field conditions, a single-wavelength model consistently estimated EW with an average RMSE of $1.24 \mathrm{mg} \cdot \mathrm{dm}^{-2}$ utilizing ground and aerial canopy reflectance.

Conclusions: Overall, the indices EWI-1, EWI-13 and the model EWM-7 are reliable tools for indirect selection for EW based on leaf reflectance, and the indices EWI-4, EWI-9 and the model EWM-1 are reliable for selection based on canopy reflectance. However, further research is needed to define how the background effects and geometry of the canopy impact the accuracy of these phenotyping methods.
\end{abstract}

Keywords: Plant cuticle, Vegetation indices, High-throughput phenotyping, Wheat breeding

\section{Background}

Wheat is a major staple food and an important source of calories in developing countries [1]. More than 220 million ha of wheat is cultivated worldwide [2], and 600 million tons of wheat grain is produced each year [3]. The expected global population of 9 billion by 2050 will

\footnotetext{
*Correspondence: camarillo.castillo.f@gmail.com

${ }^{1}$ Global Wheat Program, International Maize and Wheat Improvement Center (CIMMYT), Apdo. Postal 6-641, Mexico, D.F 06600, Mexico

Full list of author information is available at the end of the article
}

require an increase in wheat production of $60 \%$ to $100 \%$ $[2,4]$, but the current genetic gains of $<1 \%$ per year [5] will be insufficient to fulfill this expected demand. Annually, more than 600 million tons of wheat are harvested [6], but maintaining this production is already a challenge in the face of climate change. It is estimated that climate change can reduce global wheat production by $6 \%$ for every degree centigrade increase in the temperature [7]. Therefore, the development of wheat cultivars that are adapted to high temperatures and limited irrigation is 
crucial for responding to a changing climate and ensuring wheat production.

Developing wheat cultivars that are adapted to a wide range of environments, have resilience to abiotic stresses and high yield potential are priorities of the main public breeding programs [2]. Physiological trait-based improvements for tolerance to heat and drought stress rely on the favorable expression of morphological and physiological plant traits (PT) [8-10]. Independent conceptual models for grain yield (GY) under heat and drought have been proposed based on the following main drivers: light interception (LI), radiation use efficiency (RUE), partitioning of total assimilates [8], water use efficiency (WUE) and harvest index [11]. Each of these main drivers contains genetically determined PTs that can potentially lead to an additive genetic effect for resilience to heat and drought when combined through strategic crossing $[12,13]$. Physiological traits such as canopy temperature $(\mathrm{CT})$ are already utilized as selection criteria in breeding pipelines $[5,10]$, but key PTs such as epicuticular wax (EW) remain unexplored because of the expensive, subjective and laborious method for phenotyping [14].

EW is the outermost layer of leaves that is located on the top of the cutin matrix and intracuticular wax [15] and consist of hydrocarbon compounds [16, 17] derived from long chains of $C_{20}$ and $C_{30}$ fatty acids $[18,19]$. The hydrophobic layer that creates the EW covers the aerial epidermis of plants maintaining the integrity of the plant against high UV radiation [20] and external environmental stresses such as insect infestation [21,22] and pathogen infection [23]. This cuticle also minimizes the water loss via transpiration in wheat $[18,24]$ and reduces leaf temperature $[25,26]$. Early studies estimated a decrease in the internal temperature of the plant by $0.7^{\circ} \mathrm{C}$ under simulated drought conditions in a glasshouse, saving $30 \mathrm{~g}$ of water per plant during the growth season and extending grain filling by 3 days [27].

Waxes and trichomes affect the interaction of the plant with the environment, particularly the reflection and absorbance of light. Surface waxes are very effective in reflecting excessive radiation in specific ranges of the spectrum, namely at 330 and $680 \mathrm{~nm}$ [28], but the main increases in radiation reflection occur at the photosynthetic active radiation (PAR) range to dissipate excess energy and avoid damage to the PSII reaction center [29, 30]. In wheat, increases in light reflectance of $12 \%$ to $35 \%$ were detected at the PAR (400 to $700 \mathrm{~nm}$ ) range in wax covered genotypes [31]. Several studies have reported that EW and its constituents are an important protective barrier against harmful UV-B radiation [20, 28, 32-35], but these fluctuations in reflectance are species-specific and can range from $<10 \%$ in most species to $70 \%$ in others $[21,36]$.

Limitations on field phenotyping restrict our capacity to unravel complex morphological and physiological traits. Spectral technologies have the potential to increase the efficiency, precision and accuracy of phenotyping platforms. In breeding programs, high-precision phenotyping can enable the screening of segregating material, advanced lines and germplasm [5, 37]. Increasing the accuracy of phenotyping can provide more reliable estimates of heritability and variance components [38], facilitate gene discovery and enable prediction of complex traits with approaches such as genomic selection $[39,40]$. The strong association of spectral secondary traits with GY $[41,42]$ highlights the potential of canopy reflectance to increase productivity in wheat. A detailed list of sensors and their applications for plant phenotyping is provided by [43].

Recent advances in technology have maximized the throughput of phenotyping measurements under field and controlled conditions [44-46]. RGB and hyperspectral sensors have enabled the rapid and noninvasive acquisition of spectral information. Spectral vegetation indices (SVI) are a quick, easy and inexpensive method of transforming light reflectance into simple indicators of photosynthetic and canopy variations. The simple ratio index (SR) [47] and the normalized difference vegetation index (NDVI) [48] are two of the first SVIs developed for detecting green vegetation. Both indices combine the percentage of reflectance at the wavelengths where plants absorb ( 750 to $800 \mathrm{~nm})$ and reflect $(800$ to $2500 \mathrm{~nm}$ ) light. Several other SVIs have been built for sensing the water content of plants [49], photosynthetic radiation [50], carotenoid pigments [51], plant height [52], leaf area [53], and diseases [54].

In this study, the aim was to develop spectral methods to indirectly phenotype EW accumulated on the surface of leaves. This wax index will serve as a proxy to detect genotypes with a thick wax cover, in order to integrate the trait into breeding pipelines to enhance resilience to heat and drought stress. The goal is to facilitate frequent screening for EW at multiple field trial locations by replacing conventional sample-based methods. Additionally, these methods will support ongoing research on the underlaying physiological and genetic mechanisms of cuticular waxes. We conducted a set of theoretical studies with the following specific objectives: i) detect the wavelengths at which reflectance is affected by cuticular waxes, ii) develop spectral indices and models to detect wheat cultivars with high and low EW content, and iii) validate the spectral methods for phenotyping under field conditions. 
(See figure on next page.)

Fig. 1 Variation in a absorbance, $\mathbf{b}$ transmittance and $\mathbf{c}$ reflectance derived by the removal of the EW coat with HPLC chloroform (CHCl3). These variations are presented as the difference of the spectral signature of the leaf after the wax coat was removed minus the the spectral response of the leaf with the wax coat in place. The red solid lines define the red edge and the dash line mark the end of the visible and start of the NIR region. The slope of the linear regression models (d) were fitted as $Y=a+b X$, where $Y$ corresponds to the independent variable EW $\left(\mathrm{mg} \cdot \mathrm{dm}^{-2}\right), X$ is the percentage of light reflectance at one nanometer resolution, $a$ and $b$ are the intercept and the slope of the fitted model, respectively. The statistical significance of the models was $P \leq 0.05$ or less

\section{Results}

\section{Light interactions associated with leaf EW}

The differences in the light interactions detected after the removal of EW confirmed the role of the cuticle in avoiding and dissipating excess radiation (Fig. 1). Variations in the percentage of light absorbed (Fig. 1a), transmitted (Fig. 1b) and reflected (Fig. 1c) by leaves were detected when EW was partially eliminated. The removal of the cuticle increased the light absorbance in the visible range from 0.02 to $0.04 \%$, with a subsequent decrease to $0 \%$ reflectance at $710 \mathrm{~nm}$ and $0.03 \%$ in the NIR. An increase in light transmission through the leaf from 0.01 to $0.06 \%$ in the visible region was also observed, with a significant increment of $0.13 \%$ in the red-edge (680 to $740 \mathrm{~nm}$ ). In the NIR (740 to $980 \mathrm{~nm}$ ), the transmittance also increased by approximately $0.06 \%$. Light reflectance was most affected when the wax cuticle was removed. Its removal revealed that EW contributed from $0.05 \%$ to $0.15 \%$ of the increase in reflectance at various wavelengths. Further analysis enabled the estimation of both positive and negative variations in the percentage of light reflected by the unit $\left(\mathrm{mg} \cdot \mathrm{dm}^{2}\right)$ of wax accumulated on top of the leaf surface. Figure 1d presents the slopes of the linear regression models individually fitted with the EW content as the independent variable and the percentage of light reflectance detected with the spectroradiometer as the dependent variable. From 424 to $450 \mathrm{~nm}$, there was an increase of $\sim 0.82 \%$ in reflectance, and from 544 to $575 \mathrm{~nm}$ the increase was $0.79 \%$. The light reflectance in the 700 and $730 \mathrm{~nm}$ was not affected by the cuticular wax; however, there was a reduction of $0.77 \%$ from 713 to $720 \mathrm{~nm}$, with the highest peak in $717 \mathrm{~nm}(-0.8 \%)$, and a subsequent increase of $\sim 1.5 \%$ from 756 to $825 \mathrm{~nm}$.

The partial least square regression (PLSR) analysis reduced the total number of spectral bands and integrated only uncorrelated bands in the predictive model (Fig. 2). The correlation coefficients of the regression between the wavelengths and EW content are presented in Fig. 2a. Three main components enabled the maximum correlation between the wavelengths and the EW content and explained $97.34 \%$ of the variability of the trait. These three components combine the follow spectral regions: 424 to $448,625,660,712$ to 727,775 to 835 , 994 and $997 \mathrm{~nm}$. Most of these wavelengths coincide with the regions detected in Fig. 1d. The most influential variables were 712 to $727 \mathrm{~nm}$, where the transition from low reflectance in the visible region to high reflectance in the NIR wavelengths occurs. Overall, the selected latent variables or wavelengths enabled the prediction of EW content in the data subset for validation and lead to a positive linear association between the predicted and the actual values of EW (Fig. 2b).

\section{Spectral indices for indirect phenotyping of EW}

Spectral indices developed in previous studies for indirect phenotyping of morphological and physiological characteristics of the plant (Tables 1 and 2) were calculated and statistically associated with EW. The spectral resolution of the light reflectance extracted from the spectroradiometer was adjusted from 1 to $3 \mathrm{~nm}$ by averaging the percentage of light reflectance of every 3 bands. The broad spectral bands were calculated by estimating the average of reflectance $\mathrm{w}$ ithin the range $(\mathrm{nm})$ corresponding to the blue, green, yellow, orange, red, red-edge and near infrared regions. The ranges in nm of every spectral region are included in Table 2 . The narrow spectral indices PRI-1 $(r=-0.57)$, CARI-2 $(r=-0.67)$, PSSR$\mathrm{b}(\mathrm{r}=-0.57)$, PSSR-a $(\mathrm{r}=-0.55)$, ARI-1 $(\mathrm{r}=-0.52)$, ARI-2 $(\mathrm{r}=-0.58)$ and SIPI-2 $(-0.61)$ were significantly correlated $(p<0.001)$ with EW. These indices are effective to detect variations in carotenoids, chlorophyll and anthocyanins in plants [51,55-58]. However, these indices were not able to predict more than $38 \%$ of the total variability of EW. Among the broad vegetation indices calculated, only RGRI $(-0.57)$ and ARI-1 $(-0.67)$ were strongly associated with EW.

The broad and narrow indices developed in this study are presented in Table 3 . The selection of these indices was based on their high $\mathrm{R}^{2}$ in the cross validation (LOOCV) and low root mean square error (RMSE) estimates in the bootstrapping analysis. EWI-13 and EWI-14 estimated $65 \%$ and $62 \%$ of the EW variation combining the wavelengths 625, 736 and $832 \mathrm{~nm}$. The indices EWI6, EWI-9 and EWI-12 integrated only two wavelengths, 658 and $712 \mathrm{~nm} ; 670$ and $718 \mathrm{~nm}$; and 622 and $718 \mathrm{~nm}$, respectively. The proportion of the variance in the EW explained by the EWI $\left(\mathrm{R}^{2}\right)$ was as follow: EWI- $6=0.52$, EWI-9 $=0.51$ and EWI-12=0.51. When the broad spectral bands blue, red and NIR were combined in the spectral indices, the prediction accuracy ranged from 31 to 
(a) Absorbance

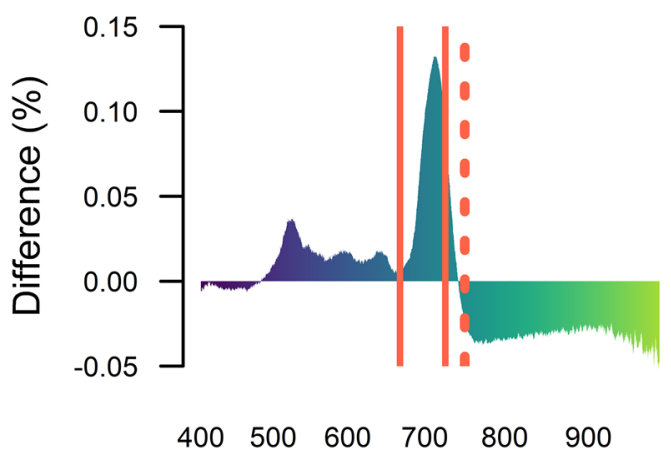

Wavelength $(\mathrm{nm})$ (b) Transmittance

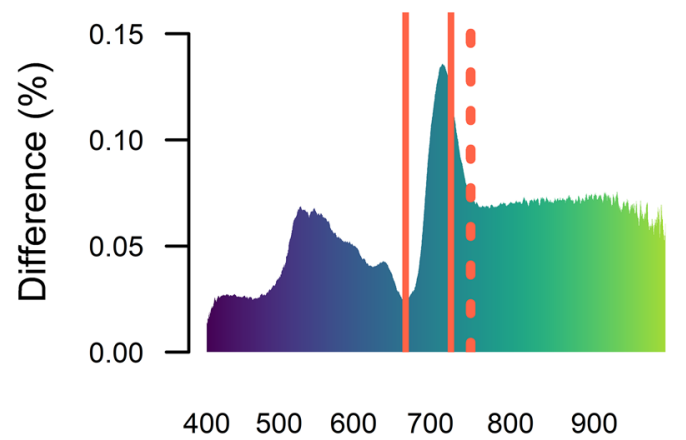

Wavelength (nm)

(c) Reflectance

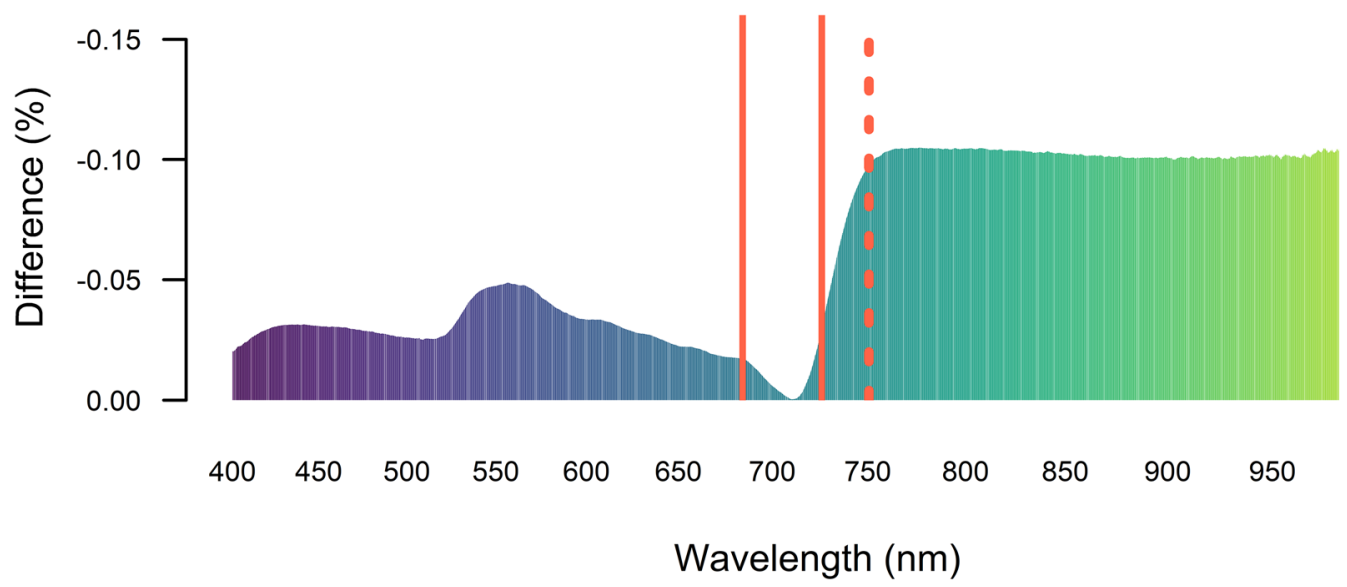

(d)
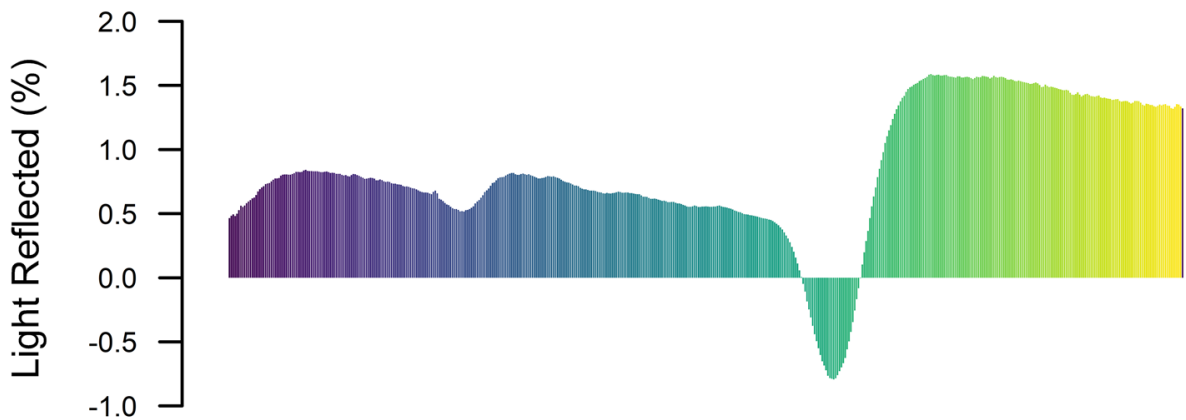

$\begin{array}{lllllllllll}400 & 450 & 500 & 550 & 600 & 650 & 700 & 750 & 800 & 850 & 900\end{array}$

Wavelength $(\mathrm{nm})$ 

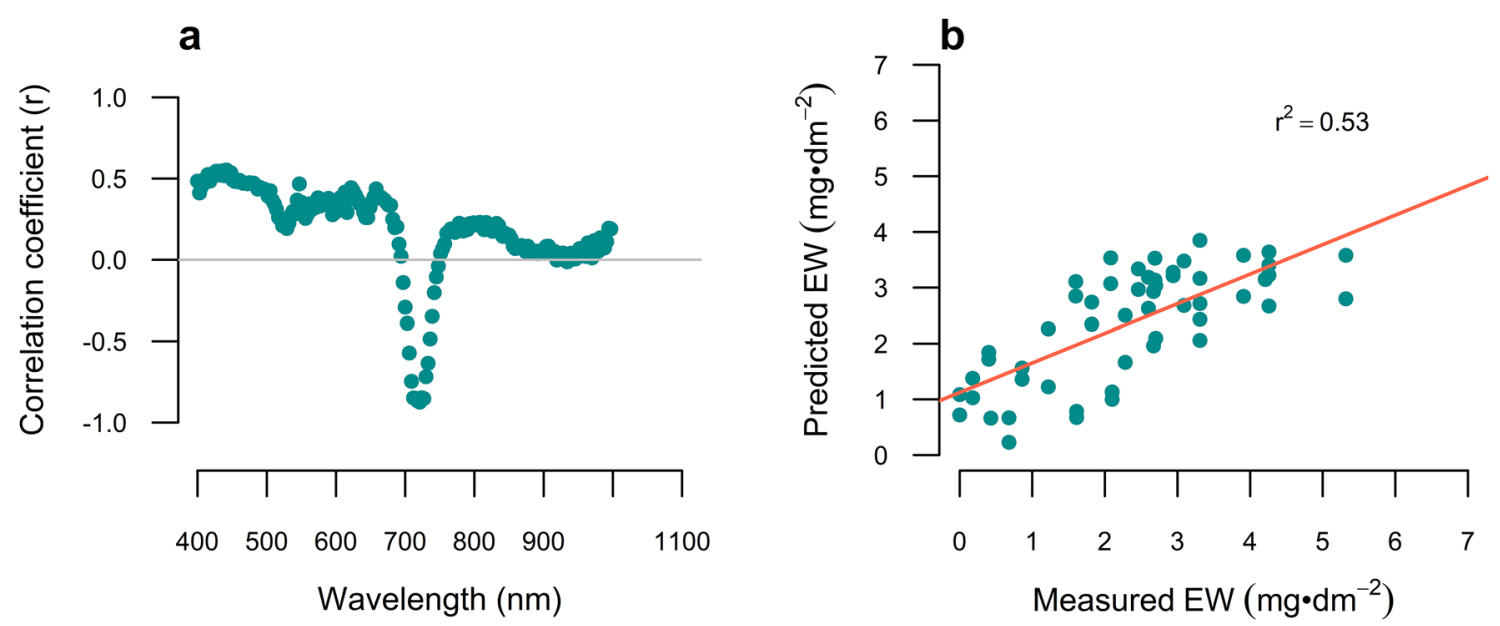

Fig. 2 Correlation coefficients $\mathbf{a}$ of the three main partial least square components with the EW content $\left(\mathrm{mg} \cdot \mathrm{dm}^{2}\right)$ and $\mathbf{b}$ association of the EW load predicted with the PLS's model vs EW measured by the chemical method

Table 1 Narrow vegetation indices for phenotyping specific traits in plants

\begin{tabular}{llll}
\hline Narrow vegetation indices & Abbreviation & Formula & Reference \\
\hline Water index & WI & $\rho_{900} / \rho_{970}$ & $\left(\rho_{531}-\rho_{570}\right) /\left(\rho_{531}+\left(\rho_{570}\right)\right.$ \\
Photochemical reflectance index & PRI-1 & $\left(\rho_{570}-\rho_{539}\right) /\left(\rho_{570}+\rho_{539}\right)$ & {$[49]$} \\
Photochemical reflectance index & PRI-2 & $\rho_{690} / \rho_{550}$ & {$[51]$} \\
Red-green index & RGI & $\rho_{970} / \rho_{900}$ & {$[68]$} \\
Normalized difference water index & NDWI & $\rho_{510} / \rho_{550}$ & {$[76]$} \\
Carotenoids reflectance index-1 & CARI-1 & $\left(1 / \rho_{510}\right) /\left(1 / \rho_{700}\right)$ & {$[49]$} \\
Carotenoids reflectance index-2 & CARI-2 & $\left(\rho_{680}-\rho_{500}\right) /\left(\rho_{750}\right)$ & {$[55]$} \\
Plant senescence reflectance index & PSRI & $\left(\rho_{680}-\rho_{430}\right) /\left(\rho_{680}+\left(\rho_{430}\right)\right.$ & {$[55]$} \\
Normalized pigment chlorophyll index & NPCI & $\rho_{800} / \rho_{650}$ & {$[77]$} \\
Pigment specific simple ratio for chlorophyll-a & PSSR-b & $\rho_{800} / \rho_{675}$ & {$\left[1 / \rho_{550}\right) /\left(1 / \rho_{700}\right)$} \\
Pigment specific simple ratio for chlorophyll-b & PSSR-a & $\rho_{800}\left(1 / \rho_{550}\right) /\left(1 / \rho_{700}\right)$ & {$[78]$} \\
Anthocyanin reflectance index-1 & ARI-1 & $\left(\rho_{800}-\rho_{450}\right) /\left(\rho_{800}+\left(\rho_{650}\right)\right.$ & {$[78]$} \\
Anthocyanin reflectance index-2 & ARI-2 & $\left.\rho_{800}-\rho_{440}\right) /\left(\rho_{800}+\left(\rho_{680}\right)\right.$
\end{tabular}

44\%. Specifically, EWI-1 estimated $44 \%$ of the variability with a RMSE of $1.19 \mathrm{mg} \cdot \mathrm{dm}^{-2}$. The slope of the linear models (B) in most cases was positive, except those for EWI-3, EWI-4, EWI-8, EWI-10 and EWI-11. The increase in EW content of $1 \mathrm{mg} \cdot \mathrm{dm}^{-2}$ caused wide variations in the values of the broad and narrow indices from 0.002 to 5.73 .

\section{Prediction accuracy of spectral indices for phenotyping of EW load}

The EW content determined with the chemical method from samples collected in the field experimental trials of the mapping population ranged from 1.54 to
$2.4 \mathrm{mg} \cdot \mathrm{dm}^{-2}$ (Table 4). The heritability estimate $\left(\mathrm{h}^{2}\right)$ of $\mathrm{EW}$ ranged from 0.51 to 0.58 across all three trials. Overall, the CV of all trials was low, 6.9 in DS-1, 5.8 in DS-2 and 7.6 in DS-3. All fourteen indices included in Table 3 were calculated with ground spectral information. However, only the indices EWI-1, EWI-2, EWI-3, EWI-4, EWI-9 and EWI-13 were strongly associated with EW deposition when estimated with canopy reflectance and are the only indices included and discussed in Table 4.

The phenotypic $\left(r_{p}\right)$ and genotypic $\left(r_{g}\right)$ correlations of the top performing indices estimated with the ground hyperspectral information and EW content are presented in Fig. 3. All correlations were statistically 
Table 2 Broad band vegetation indices for phenotyping specific traits in plants

\begin{tabular}{|c|c|c|c|}
\hline Broad band VI & Abbreviation & Formula & Reference \\
\hline Violet wavelength & $\mathrm{VIO}$ & $\rho_{400} / \rho_{451}$ & \\
\hline Blue wavelength & $B L$ & $\rho_{454}$ to $\rho_{496}$ & \\
\hline Green wavelength & GR & $\rho_{499}$ to $\rho_{517}$ & \\
\hline Yellow wavelength & YW & $\rho_{574}$ to $\rho_{589}$ & \\
\hline Orange wavelength & OR & $\rho_{592}$ to $\rho_{619}$ & \\
\hline Red wavelength & RED & $\rho_{622}$ to $\rho_{748}$ & \\
\hline Red-edge wavelength & RE & $\rho_{691}$ to $\rho_{730}$ & \\
\hline Near infrared wavelength & NIR & $\rho_{751}$ to $\rho_{997}$ & \\
\hline Normalized difference vegetation index & NDVI & $(N I R-R e d) /(N I R+R e d)$ & [48] \\
\hline Simple ratio index & SR & NIR/Red & [47] \\
\hline Green normalized difference vegetation index & NDVI-green & $($ NIR - Green $) /($ NIR + Green $)$ & {$[79]$} \\
\hline Modified simple ratio & MSR & $\operatorname{Red} /(\text { NIR/Red }+1)^{0.5}$ & {$[80]$} \\
\hline Renormalized difference vegetation index & RDVI & $(N I R-R e d) /(N I R+R e d)^{0.5}$ & [81] \\
\hline Red-green vegetation index & RGRI & Red - Green & {$[82]$} \\
\hline Ratio vegetation index & $\mathrm{RVI}$ & Red/NIR & {$[76]$} \\
\hline Difference vegetation index & DVI & NIR - Red & {$[83]$} \\
\hline SR \& NDVI & SR-NDVI & $\left(N I R^{2}-R e d\right) /\left(N I R+\operatorname{Red}^{2}\right)$ & [53] \\
\hline NDVI-Red-edge & NDVI-RE & $\left(N I R-\operatorname{Red}_{\text {edge }}\right) /(N I R+$ Red edge $)$ & [76] \\
\hline Red $_{\text {edge }}$ chlorophyll index & $\mathrm{Cl}_{\text {-Red }}$ edge & $\left(N I R / R_{e d}\right.$ edge $)-1$ & [76] \\
\hline Anthocyanin reflectance index & ARI-1 & $(1 /$ Green $) /\left(1 /\right.$ Red $\left._{\text {edge }}\right)$ & {$[76]$} \\
\hline Modified Anthocyanins reflectance index & mARI & $(1 /$ Green $) /\left(1 /\right.$ Red $\left._{\text {edge }}\right) * N I R$ & {$[76]$} \\
\hline Anthocyanin reflectance index & ARI-2 & Green/NIR & $(76)$ \\
\hline
\end{tabular}

Table 3 Coefficients of determination $\left(R^{2}\right)$ and root mean square error (RMSE in $\mathrm{mg} \cdot \mathrm{dm}^{-2}$ ) of the indices developed for phenotyping $E W$ in leaves

\begin{tabular}{|c|c|c|c|c|c|c|}
\hline \multirow[t]{2}{*}{ Index } & \multicolumn{6}{|c|}{ Model parameters } \\
\hline & $\bar{a}$ & B & $\mathrm{R}^{2}$ & RMSE & $95 \% \mathrm{Cl}$ & p-value \\
\hline \multicolumn{7}{|c|}{ Broad indices / RGB and NIR spectral bands } \\
\hline EWI-1 ${ }_{\text {Blue/Red }}$ & 0.213 & 0.04 & 0.44 & 1.19 & $1.037-2.17$ & $<0.0001$ \\
\hline EWI-2 Blue/NIR & 0.07 & 0.13 & 0.39 & 1.18 & $0.98-1.98$ & $<0.0001$ \\
\hline EWI-3 (NIR-Red)/Blue & -0.93 & -0.01 & 0.31 & 1.19 & $1.04-1.97$ & $<0.0001$ \\
\hline EWI-4 (Red ${ }^{2}$-Blue)/(Red-Blue $\left.{ }^{2}\right)$ & -0.09 & -0.03 & 0.32 & 1.19 & $1.09-2.55$ & $<0.0001$ \\
\hline \multicolumn{7}{|c|}{ Narrow indices / two narrow spectral bands } \\
\hline EWI-5 676 & 0.019 & 0.005 & 0.45 & 0.97 & $0.75-1.21$ & $<0.0001$ \\
\hline EWI-6 $658 / 712$ & 0.12 & 0.03 & 0.52 & 1.02 & $0.70-1.36$ & $<0.0001$ \\
\hline EWI-7 625/706 & 0.22 & 0.05 & 0.50 & 0.96 & $0.67-1.28$ & $<0.0001$ \\
\hline EWI-8 $694 / 625$ & -0.006 & -0.002 & 0.42 & 1.08 & $0.96-1.55$ & $<0.0001$ \\
\hline EWI-9 $(670-718) /(670+718)$ & -0.85 & 0.03 & 0.51 & 1.04 & $0.61-1.54$ & $<0.0001$ \\
\hline EWI-10 $(691-661) /(691+661)^{2}$ & 4.92 & -1.03 & 0.48 & 0.99 & $0.74-1.27$ & $<0.0001$ \\
\hline EWI-1 $1_{(1 / 661)-(1 / 694)}$ & 29.13 & -5.73 & 0.48 & 1.01 & $0.71-1.35$ & $<0.0001$ \\
\hline $\mathrm{EWI}-12_{(622 / 718)-1}$ & 0.62 & 0.12 & 0.51 & 0.99 & $0.74-1.28$ & $<0.0001$ \\
\hline \multicolumn{7}{|c|}{ Narrow indices / three narrow spectral bands } \\
\hline EWI-13 $625(1 / 736-1 / 832)$ & 0.008 & 0.004 & 0.65 & 1.01 & $0.622-1.426$ & $<0.0001$ \\
\hline EWI-14 (625-736) / 832 & 0.02 & 0.007 & 0.62 & 0.98 & $0.65-1.35$ & $<0.0001$ \\
\hline
\end{tabular}

$\mathrm{R}^{2}$ was calculated in the training set by a leaving one out cross validation analysis (LOOCV) and the RMSE was estimated in the validation set. $\mathrm{B}$ is the slope of the line and $\mathrm{a}$ is the intercept of the dependent variable 
Table 4 Mean, genetic variance $\left(\boldsymbol{\sigma}_{\boldsymbol{g}}^{2}\right)$, heritability estimate $\left(\boldsymbol{h}^{2}\right)$, error variance $\left(\boldsymbol{\sigma}_{\boldsymbol{e}}^{2}\right)$ and coefficient of variation (CV in \%) of EW content $\left(\mathrm{mg} \cdot \mathrm{dm}^{-2}\right)$, EWI-1, EWI-2, EWI-3, EWI-4, EWI-9 and EWI-13

\begin{tabular}{|c|c|c|c|c|c|c|}
\hline & & Mean & $\sigma_{g}^{2}$ & $h^{2}$ & $\sigma_{e}^{2}$ & CV \\
\hline \multirow[t]{3}{*}{$\mathrm{EW}\left(\mathrm{mg} \cdot \mathrm{dm}^{-2}\right)$} & DS-1 & 1.72 & 0.014 & 0.56 & 0.014 & 6.9 \\
\hline & DS-2 & 2.40 & 0.015 & 0.51 & 0.018 & 5.8 \\
\hline & DS-3 & 1.54 & 0.016 & 0.58 & 0.014 & 7.6 \\
\hline \multirow[t]{3}{*}{ EWI-1 } & DS-1 & 0.31 & 0.00039 & 0.78 & 0.00025 & 5.0 \\
\hline & DS-2 & 0.37 & 0.0004 & 0.86 & 0.0001 & 2.9 \\
\hline & DS-3 & 0.41 & 0.0007 & 0.78 & 0.0004 & 5.2 \\
\hline \multirow[t]{3}{*}{ EWI-2 } & DS-1 & 0.31 & 0.00039 & 0.83 & 0.00025 & 5.1 \\
\hline & DS-2 & 0.17 & 0.0003 & 0.77 & 0.0002 & 7.9 \\
\hline & DS-3 & 0.41 & 0.00001 & 0.46 & 0.0004 & 5.2 \\
\hline \multirow[t]{3}{*}{ EWI-3 } & DS-1 & 6.72 & 2.07 & 0.85 & 0.72 & 12.6 \\
\hline & DS-2 & 3.2 & 0.34 & 0.78 & 0.19 & 13.7 \\
\hline & DS-3 & 26.6 & 7.4 & 0.48 & 16.5 & 13.9 \\
\hline \multirow[t]{3}{*}{ EWI-4 } & DS-1 & -1.28 & 0.0006 & 0.58 & 0.0008 & 22.7 \\
\hline & DS-2 & -0.23 & 0.0003 & 0.65 & 0.0002 & 6.8 \\
\hline & DS-3 & -0.37 & 0.0007 & 0.80 & 0.0003 & 5.3 \\
\hline \multirow[t]{3}{*}{ EWI-9 } & DS-1 & -0.48 & 0.0065 & 0.84 & 0.0024 & 10.2 \\
\hline & DS-2 & -0.28 & 0.0016 & 0.74 & 0.0011 & 12.1 \\
\hline & DS-3 & -0.12 & 0.00006 & 0.63 & 0.00007 & 7.3 \\
\hline \multirow[t]{3}{*}{ EWI-13 } & DS-1 & 0.72 & 0.0001 & 0.75 & 0.00007 & 11.5 \\
\hline & DS-2 & 0.092 & 0.000039 & 0.78 & 0.000023 & 5.2 \\
\hline & DS-3 & 0.29 & 0.0001 & 0.62 & 0.0001 & 3.6 \\
\hline
\end{tabular}

EW and the indices were estimated across three sets of data (DS 1 to 3) collected from wheat inbreed lines evaluated during the agronomic cycle from 2012 to 2013 , 2014 to 2015 and 2016 in the research station of CIMMYT near at Ciudad Obregon, Sonora in Mexico and Bushland, Texas

(See figure on next page.)

Fig. 3 Phenotypic $\left(\sigma_{p}\right)$ and genotypic $\left(\sigma_{g}\right)$ correlation of the epicuticular wax indices (EWI) 1, 2, 3, 4, 9 and 13 with EW content measured with the chemical method $\left(\mathrm{mg} \cdot \mathrm{dm}^{-2}\right)$. All six indices were statistically significant $(P<0.01)$ across all three sets $(\mathrm{DS}-1,2$ and 3$)$

significant at $P \leq 0.01$. As expected, genotypic correlations were higher than phenotypic correlations in all cases. According to these parameters, the index EWI-4 and EWI-9 better estimated the variation of EW. The average response of $r_{p}$ and $r_{g}$ were -0.51 and -0.55 for the EWI-4, and 0.33 and 0.48 for EWI-9.

Although the lack of variance of EW in the mapping population used in this study might limit the response for direct selection, the moderate $\mathrm{h}^{2}$ of the trait would lead to genetic advances when selection is applied (Table 5). The genetic gain (GG) for EW with selection pressure of $10 \%$ is also included in Table 5 . In DS-1, the GG was $0.65 \mathrm{mg} \cdot \mathrm{dm}^{-2}$; in DS-2, it was $0.89 \mathrm{mg} \cdot \mathrm{dm}^{-2}$, and in DS-3 it was $0.59 \mathrm{mg} \cdot \mathrm{dm}^{-2}$. However, when the mean of the actual population was considered, the genetic advance with direct selection averaged $2.5 \%$. The correlated response of the EW indices with the EW content derived an increase in EW. Improvement in the EWI-1, 2, 9 and 13 resulted in increases of $0.063,0.053,0.047$ and $0.043 \mathrm{mg} \cdot \mathrm{dm}^{-2}$ of EW content, respectively. On the other hand, decreases of 0.047 and $0.063 \mathrm{mg} \cdot \mathrm{dm}^{-2}$ were calculated with a positive selection of the indices EWI-3 and 4. The efficiency of selection (RE) based on the secondary characters or indices (EWI) ranged from 46 to $78 \%$ in average. However, EWI-1, 2 and 4 in DS-2 were almost as efficient in selection as the direct selection of the trait with the chemical method with 112,99 and $90 \%$ efficiency, respectively.

\section{Multivariate regression models integrating narrow spectral bands to predict the EW load}

The statistics of the multivariate models developed with the selected bands in the PLSR analysis are presented in Table 6 . The final selection of the variables led to seven models in single and/or multiple combinations of eight wavelengths. The spectral response at $424 \mathrm{~nm}$ predicted almost 33\% 
(a)

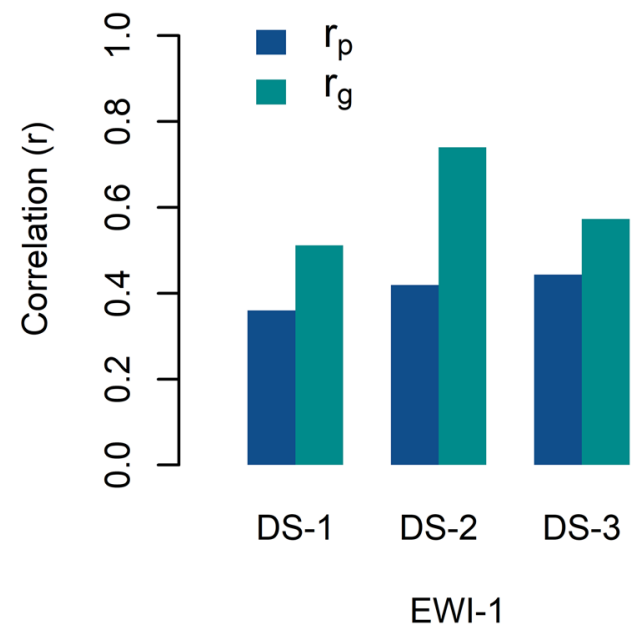

(c)

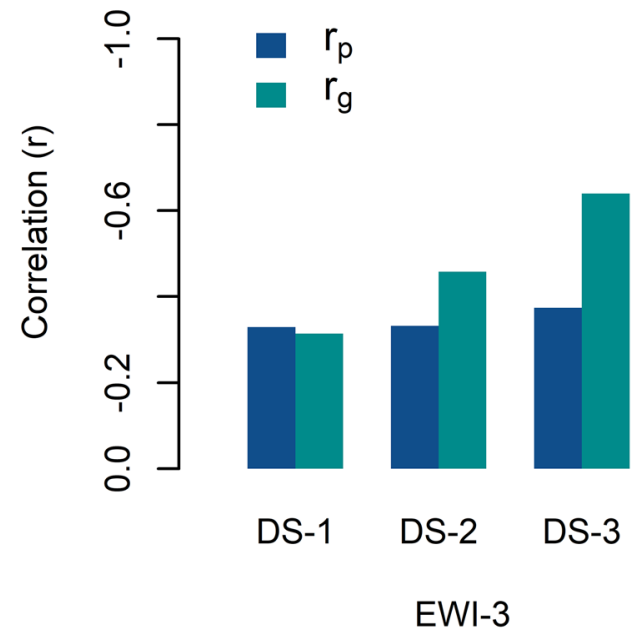

(e)

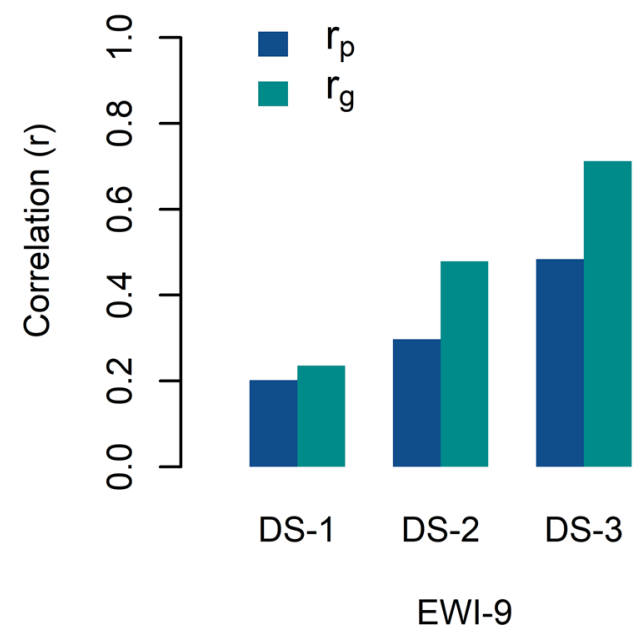

(b)

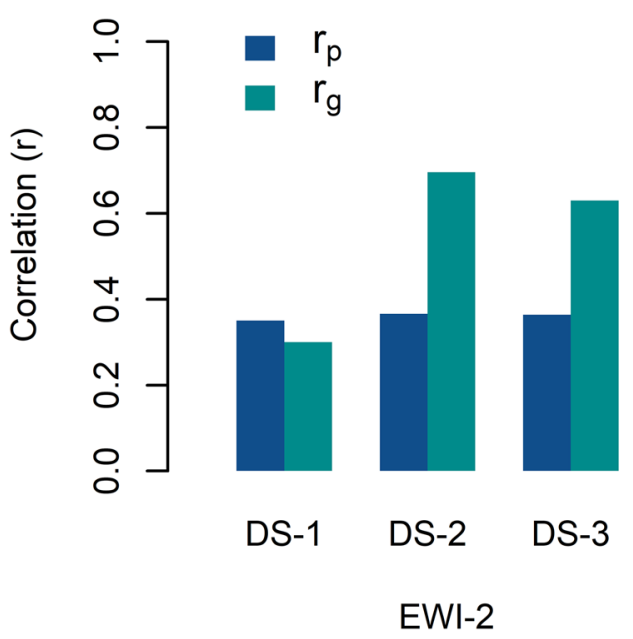

(d)

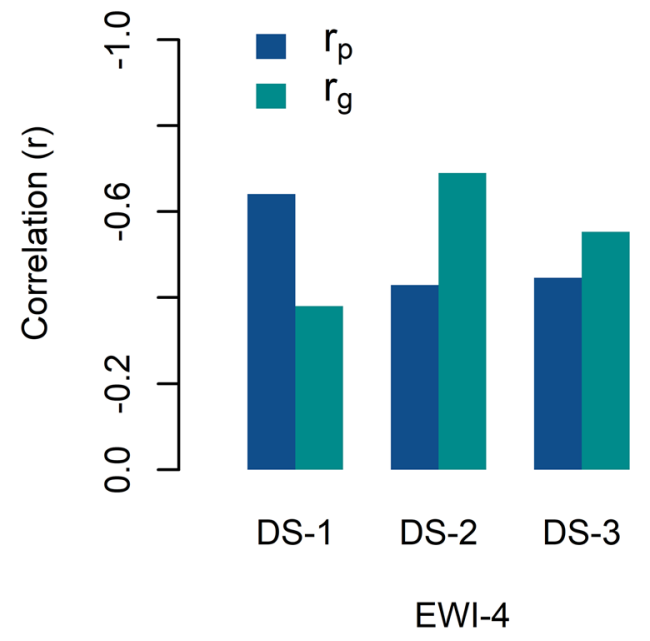

(f)

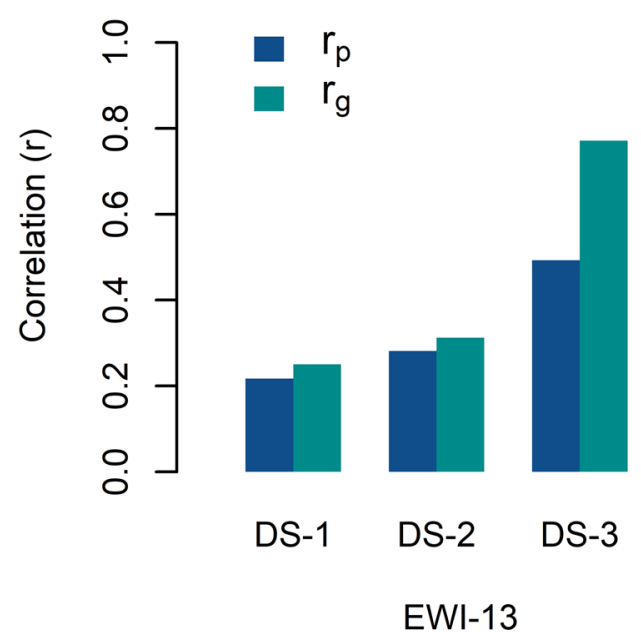


Table 5 Genetic gain ( $G G$ in $\mathrm{mg} \cdot \mathrm{dm}^{-2}$ ), genetic advance with respect to the mean (GAM in \%) and response to direct selection (R) of EW

\begin{tabular}{|c|c|c|c|c|}
\hline & & DS-1 & DS-2 & DS-3 \\
\hline GG & EW & 0.65 & 0.89 & 0.59 \\
\hline GAM (\%) & EW & 2.5 & 1.7 & 3.3 \\
\hline $\mathrm{R}$ & EW & 0.09 & 0.08 & 0.12 \\
\hline$C R$ & EW \& EWI-1 & 0.05 & 0.08 & 0.06 \\
\hline$C R$ & EW \& EWI-2 & 0.03 & 0.08 & 0.05 \\
\hline$C R$ & EW \& EWI-3 & -0.03 & -0.05 & -0.06 \\
\hline$C R$ & EW \& EWI-4 & -0.06 & -0.07 & -0.06 \\
\hline$C R$ & EW \& EWI-9 & 0.02 & 0.05 & 0.07 \\
\hline$C R$ & EW \& EWI-13 & 0.02 & 0.03 & 0.08 \\
\hline RE & EW \& EWI-1 & 0.65 & 1.12 & 0.55 \\
\hline RE & EW \& EWI-2 & 0.46 & 0.99 & 0.46 \\
\hline RE & EW \& EWI-3 & -0.41 & -0.66 & -0.48 \\
\hline RE & EW \& EWI-4 & -0.71 & -0.90 & -0.53 \\
\hline RE & EW \& EWI-9 & 0.27 & 0.67 & 0.62 \\
\hline RE & EW \& EWI-13 & 0.26 & 0.45 & 0.66 \\
\hline
\end{tabular}

Correlated response (CR) of EW content and indices, and relative efficiency of indirect selection (RE) of EW with indices 1, 2, 3, 4, 9, and 13
The RMSE of the seven EW models was estimated in the four experimental trials in which ground and aerial reflectance were collected. The square root of the residuals is presented in Fig. 4a. A considerable increase in the error of the prediction models calculated with ground and aerial hyperspectral information was observed across all trials in comparison to the RMSE estimated with reflectance from single leaves. The highest prediction accuracy was obtained with EWM-1, with an average RMSE of $1.4 \mathrm{mg} \cdot \mathrm{dm}^{-2}$ from the ground measurements and of $0.63 \mathrm{mg} \cdot \mathrm{dm}^{-2}$ from the aerial information. EWM-2 seems to accurately estimate EW load utilizing light reflectance in the same way as EWI-1. However, in cases as DS-1, the prediction accuracy with the EWM-2 led to a RMSE as high as $5.7 \mathrm{mg} \cdot \mathrm{dm}^{-2}$.

\section{Discussion}

In this study we evaluated the spectral response of leaves and derived and validated a set of indirect methods for phenotyping the trait. Furthermore, differences in light interaction derived by cuticular waxes and detected in this study coincide with results from studies conducted

Table 6 Statistics of regression models (EWM)

\begin{tabular}{|c|c|c|c|c|c|c|c|c|c|c|c|}
\hline & & Spectra & and in na & neters & & & & & & RMSE & $\mathrm{R}^{2}$ \\
\hline \multirow[t]{2}{*}{ EWM-1 } & Intercept & 424 & & & & & & & & 0.49 & 0.33 \\
\hline & 0.46 & 52 & & & & & & & & & \\
\hline \multirow[t]{2}{*}{ EWM-2 } & Intercept & 658 & 721 & & & & & & & 0.50 & 0.45 \\
\hline & 0.31 & 90.3 & -3.88 & & & & & & & & \\
\hline \multirow[t]{2}{*}{ EWM-3 } & Intercept & 712 & 721 & 775 & 817 & & & & & 0.51 & 0.58 \\
\hline & 0.71 & 160.7 & -183.1 & -33.7 & 80.2 & & & & & & \\
\hline \multirow[t]{2}{*}{ EWM-4 } & Intercept & 658 & 712 & 721 & 775 & 817 & & & & 0.51 & 0.60 \\
\hline & 0.19 & 40.8 & 109.6 & -128.4 & -65.8 & 99.1 & & & & & \\
\hline \multirow[t]{2}{*}{ EWM-5 } & Intercept & 574 & 658 & 712 & 721 & 775 & 817 & & & 0.51 & 0.61 \\
\hline & -0.22 & 17.3 & 16.9 & 82.9 & -109.1 & -122.2 & 153.4 & & & & \\
\hline \multirow[t]{2}{*}{ EWM-6 } & Intercept & 424 & 574 & 658 & 712 & 721 & 775 & 817 & & 0.52 & 0.66 \\
\hline & 1.13 & -76.4 & 1.9 & 134.7 & 76.4 & -109.9 & -45.1 & 78.1 & & & \\
\hline \multirow[t]{2}{*}{ EWM-7 } & Intercept & 424 & 547 & 574 & 658 & 712 & 721 & 775 & 817 & 0.52 & 0.71 \\
\hline & -3.1 & -73.5 & 58.9 & -82.7 & 146.9 & 89.6 & -188.8 & -91.6 & 134.3 & & \\
\hline
\end{tabular}

The coefficient of determination $\left(R^{2}\right)$ and the $C(p)$ were calculated in the training set, while the root mean square error (RMSE) was estimated in the validation set. The multivariate models were significant at $5 \%$ of probability or less

Bold values indicate the parameters of the statistical model: intercept and wavelength range in nanometers $(\mathrm{nm})$

of the total variability of the trait in the validation set. However, when as many as seven spectral bands were incorporated in a model $(424,547,574,658$, $712,721,775$ and $817 \mathrm{~nm})$, the accuracy increased by $38 \%\left(E W M-7\right.$ with $\left.R^{2}=0.71\right)$. The RMSE of the prediction was consistent across the models, ranging from 0.49 to $0.52 \mathrm{mg} \cdot \mathrm{dm}^{2}$. in Vitis vinifera [59], Leucadendron lanigerum [60] and Cotyledon orbiculata [61]. The increase of approximately $10 \%$ of light reflectance in the NIR region was considerably less than changes in reflectance previously detected on wheat $\sim 15 \%$ [62] and in rosette succulent plants $~ 50 \%$ [31]. Additionally, the violet $(r=0.64)$ and blue $(r=0.63)$ spectral regions strongly correlated with EW, and it is in 


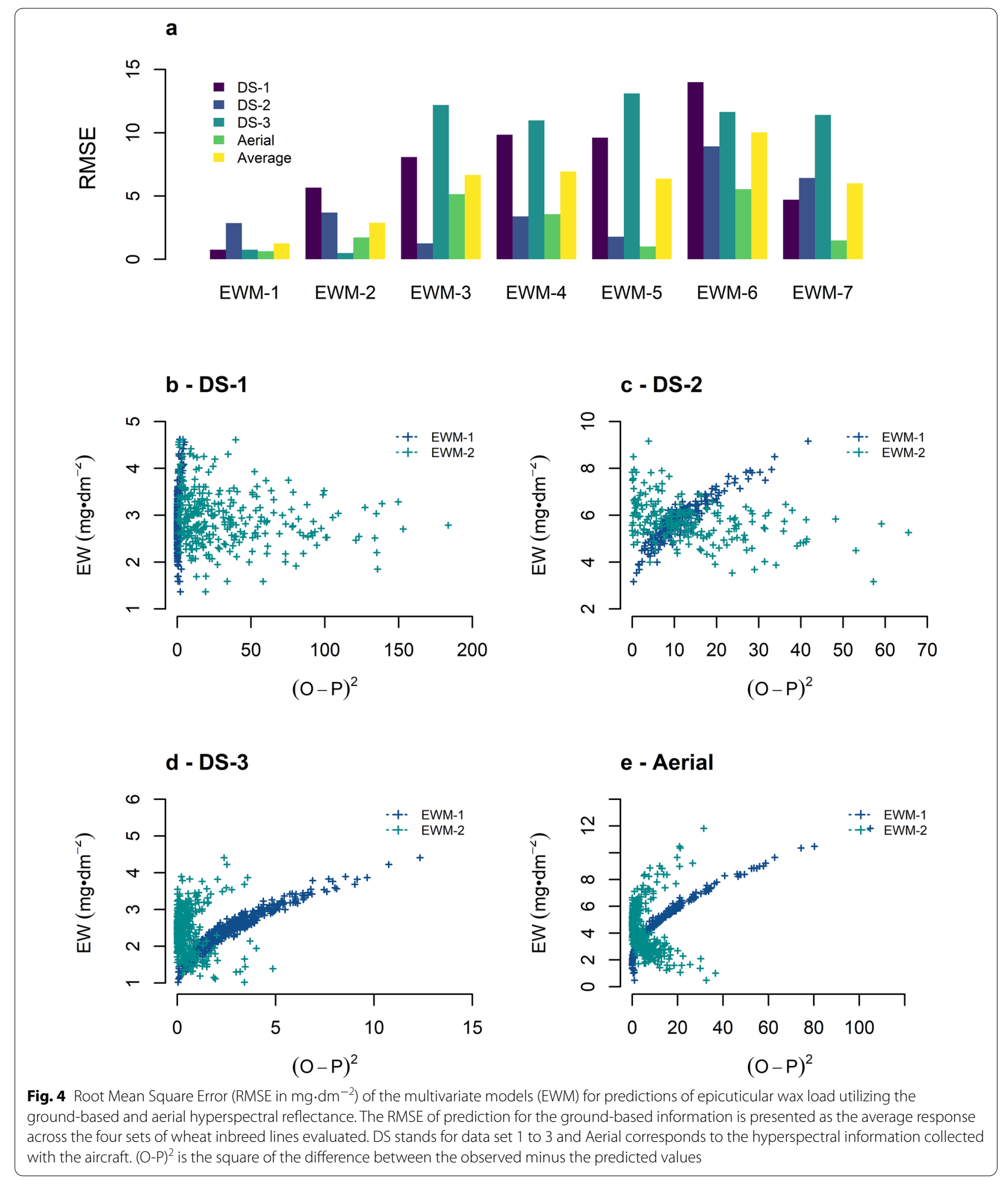

line with preliminary studies where waxes were reported as photoprotective mechanisms against short wavelength radiation [17, 63-65]. A significant number of research studies also reported that waxes enhance UV ( 100 to $400 \mathrm{~nm}$ ) reflectance $[17,28,63,66]$, but the analysis of these wavelengths is outside of the scope of this study 
Table 7 Correlation of the narrow and broad vegetation indices and the EW content $\left(\mathrm{mg} \cdot \mathrm{dm}^{-2}\right.$ )

\begin{tabular}{|c|c|c|c|}
\hline Narrow vegetation indices & $\begin{array}{l}\text { Correlation } \\
\text { coefficient }(r)\end{array}$ & Broad vegetation indices & $\begin{array}{l}\text { Correlation } \\
\text { coefficient }(r)\end{array}$ \\
\hline Water index & $-0.18^{\text {ns }}$ & Violet wavelength & $0.64^{b}$ \\
\hline Photochemical reflectance index-1 & $-0.57^{b}$ & Blue wavelength & $0.63^{b}$ \\
\hline Photochemical reflectance index-2 & $0.41^{\mathrm{b}}$ & Green wavelength & $0.48^{\mathrm{b}}$ \\
\hline Red-green index & $-0.08^{\mathrm{ns}}$ & Yellow wavelength & $0.49^{b}$ \\
\hline Normalized difference water index & $-0.45^{b}$ & Orange wavelength & $0.52^{b}$ \\
\hline Carotenoids reflectance index-1 & $0.46^{\mathrm{b}}$ & Red wavelenght & $0.33^{\mathrm{a}}$ \\
\hline Carotenoids reflectance index-2 & $-0.67^{b}$ & Red-edge wavelenght & $-0.006^{\mathrm{ns}}$ \\
\hline Plant senescence reflectance index & $-0.31^{\mathrm{a}}$ & Near infrared & $0.39^{b}$ \\
\hline Normalized pigment chlorophyll index & $-0.44^{b}$ & Normalized difference vegetation index & $0.08^{\mathrm{ns}}$ \\
\hline Pigment specific simple ratio for chlorophyll-a & $-0.57^{b}$ & Simple ratio index & $0.11^{\mathrm{ns}}$ \\
\hline Pigment specific simple ratio for chlorophyll-b & $-0.55^{b}$ & Green normalized difference vegetation index & $-0.34^{\mathrm{a}}$ \\
\hline Anthocyanin reflectance index-1 & $-0.52^{b}$ & Modified simple ratio & $0.28^{\mathrm{a}}$ \\
\hline Anthocyanin reflectance index-2 & $-0.58^{b}$ & Renormalized difference vegetation index & $0.31^{\mathrm{a}}$ \\
\hline Structure insensitive pigment index-1 & $-0.34^{b}$ & Red-green vegetation index & $-0.57^{\mathrm{b}}$ \\
\hline \multirow[t]{8}{*}{ Structure insensitive pigment index-2 } & $-0.61^{b}$ & Ratio vegetation index & $-0.08^{\text {ns }}$ \\
\hline & & Difference vegetation index & $0.37^{* *}$ \\
\hline & & Simple ratio and normalized difference vegetation index & $0.33^{\mathrm{a}}$ \\
\hline & & Normalized difference vegetation index- Red-edge & $0.42^{\mathrm{b}}$ \\
\hline & & Red $_{\text {edge }}$ chlorophyll index & $0.43^{b}$ \\
\hline & & Anthocyanin reflectance index-1 & $-0.67^{b}$ \\
\hline & & Modified Anthocyanins reflectance index & $-0.45^{b}$ \\
\hline & & Anthocyanin reflectance index-2 & $0.32^{\mathrm{a}}$ \\
\hline
\end{tabular}

ns not significant; ${ }^{\mathrm{a}}$ and ${ }^{\mathrm{b}}$ Significant at $5 \%$ and $1 \%$ probability, respectively

due to limitations of the equipment utilized to collect the spectral information.

The wax cuticle enhances light reflectance almost by $1 \%$ per every unit of wax $\left(\mathrm{mg} \cdot \mathrm{dm}^{-2}\right)$ accumulated on top of the leaf surface, but specifically in the PAR wavelengths where the absorption of photosynthetic pigments occurs [17]. In sorghum (Sorghum bicolor L.), a similar increase of $3 \%$ in reflectance by the cuticular leaf coat was reported, but the result was based on wavelengths of the spectrum from 400 to $1000 \mathrm{~nm}$, without a detailed examination of specific narrow spectral bands [67]. Among the spectral regions associated with EW, the wavelength at 424 and $448 \mathrm{~nm}$ are linked to the absorption of light by carotenoids in plants [56], while the surrounding wavelengths at approximately $500 \mathrm{~nm}$ are associated with the dissipation of excess radiation and the efficiency of photosynthetic radiation [50,68,69]. Additional peaks of absorption of chlorophyll $\mathrm{a}$ and $\mathrm{b}$ in the $600 \mathrm{~nm}$ coincides with two main wavelengths linked to EW in 625 and $660 \mathrm{~nm}$.

Several narrow and broad indices for phenotyping additional traits in plants were correlated with EW load, but the moderate to low correlation (Table 7) of these indices with EW limits any form of application for phenotyping. Although a reasonable $\mathrm{r}^{2}$ value of 0.65 was estimated when three narrow spectral bands were integrated in the novel spectral indices (EWI-13 and EWI-14 in Table 2), the high cost of sensors required to acquire hyperspectral reflectance can limit the utilization of these indices. On the contrary, EWI-1 requires two main spectral ranges (blue and red) that can easily be extracted from RGB images. Broad-sense heritability was estimated for the EW indices and the EW measured by the chemical method (Table 4). In all three trials $\mathrm{h}^{2}$ was considerably higher than in prelaminar published results [70]. The six EW indices enabled a more reliable and precise quantification of the proportion of the genetic variance of the trait by considerably decreasing the error variance. However, the coefficients of variation of the indices EWI3, EWI-4, EWI-9 and EWI-13 in DS-1 were considerably large due to the dispersion of the data around the mean of the population.

The moderated $\mathrm{h}^{2}$ of EW let to genetic gains of up to $3 \%$, a reasonable advancement for a quantitative trait and superior to genetic gains of $\sim 1 \%$ in grain yield [ 71 , 72]. All four broad and two narrow indices presented in Table 5 positively improve EW content, except EWI-3 and EWI-4, for which negative selection is needed to 
increase the EW load on leaf surfaces. The efficiency of indirect selection with the spectral indices was highly dependent on the experimental trial and its coefficient of variation, as it is the case in the DS-2 where selection with the EWI-1 was $12 \%$ more efficient that the direct selection. Examining the residuals of the model against the EW measurements, we observed a shift towards an increase in the residuals of EWI-1 as the EW content increases, suggesting a potential restriction on utilizing this index for phenotyping genotypes where the EW is above $6 \mathrm{mg} \cdot \mathrm{dm}^{-2}$. However, this was not observed with the residuals of EWM-2. We suspect that implementing the EWI developed in this study with aerial spectral reflectance might lead to a low-quality phenotyping of EW and could potentially lead to confounding results.

\section{Conclusions}

EW is the outermost cuticle of leaves and directly affects light interactions, especially reflectance. This cuticle increases light reflectance at the visible and NIR regions by $0.5 \%$ and $1.6 \%$, respectively. Integrating specific narrow wavelengths that are highly sensitive to variations in the EW load, we generated several spectral linear models and vegetation indices for predicting the EW content and detecting cultivars with low and high EW. The prediction accuracy of these phenotyping methods was dependent on the characteristics of the sensor utilized to capture the spectral information, as well as on the canopy architecture and the distance of the sensor from the ground. With light reflectance captured from either the adaxial or abaxial side of the leaf, the broad index EWI-1 and the narrow index EWI-13 can accurately estimate EW. However, for canopy reflectance, the indices EWI-4 and EWI-9 more accurately estimate the density of the cuticle and led to a similar genetic advance than that from direct selection for the trait. The multivariate regression model EWM-7 integrated eight wavelengths distributed across the visible and NIR spectra and estimated $71 \%$ of the variation of the trait from the reflectance of a single leaf. In contrast, with ground and aerial reflectance, EWM-1 and EWI-2 accurately estimated the EW content $\left(\mathrm{mg} \cdot \mathrm{dm}^{-2}\right)$, but insensitivity to variation at EW values larger than $6 \mathrm{mg} \cdot \mathrm{dm}^{-2}$ was detected for EWI-1.

\section{Methods}

\section{Plant material and culture}

The first set of genotypes evaluated were twenty-four recombinant inbred lines (RILs) derived from a cross of the spring cultivars Halberd (tolerant to heat stress) and Len (susceptible to heat stress). The lines were grown in a completely randomized design (CRD) with four replications in a growth chamber programmed with intervals of twelve hours of light and dark. Plants were sown in nursery pots $0.185 \mathrm{~m}$ in height with a diameter of $0.162 \mathrm{~m}$ that were filled with peat moss. The plants were fertilized twice during the growing season with the standard fertilizer $20-20-20\left(\mathrm{~N}-\mathrm{P}_{2} \mathrm{O}_{5}-\mathrm{K}_{2} \mathrm{O}\right)$.

\section{Leaf radiometric measurements}

The spectral response from 350 to $1050 \mathrm{~nm}$ was captured with a CI-710 miniature leaf spectrometer from CID Bio-Science in 3022 spectral channels. The equipment was calibrated every five minutes with an integrated $\mathrm{BaSO} 4$ white reference disk for $100 \%$ reflectance and a black panel for $0 \%$ reflectance. Ten readings of the light reflected by the flag leaf were obtained prior to collecting the leaf sample for wax quantification. The spectral range of the signatures were adjusted to $400-900 \mathrm{~nm}$ and the spectral resolution to $3 \mathrm{~nm}$ by averaging the spectral channels included every $3 \mathrm{~nm}$. The last step was to estimate the average of the ten spectral readings, only the averaged signature was considered for further analysis.

\section{Quantification of epicuticular wax}

Leaf samples were collected after the light reflectance at the adaxial and abaxial sides of the leaf was recorded, approximately 10 days after pollination (DAP). Each sample consisted of six leaf punches of $0.01 \mathrm{~m}$ diameter and were collected in $2.0 \mathrm{ml}(\mathrm{ml})$ glass vials. The EW was extracted by immersing the leaf punches in $1.5 \mathrm{ml}$ of HPLC chloroform $\left(\mathrm{CHCl}_{3}\right)$ for $20 \mathrm{~s}$, and the EW was quantified via the colorimetric method described by [14]. The optical density of every sample at $590 \mathrm{~nm}$ was measured with PHERAstar ${ }^{\circledR}$ spectrophotometer. A standard curve was developed to transform the readings of absorbance to milligrams $(\mathrm{mg})$ per square decimeter $\left(\mathrm{dm}^{2}\right)$ of EW.

\section{Partial least square (PLSR)}

A supervised multivariate model was built to predict EW $(Y)$ in a training set of data by applying the partial least square regression (PLSR) approach. PLSR is a statistical method that combines the theoretical principles of multiple linear regression and principal component analysis (PCA) to address the situations where several highly correlated predictor variables and relatively fewer samples exist. This approach decomposes the response variables $(X)$ into orthogonal scores $(T)$, loadings $(P)$ and the error $(E)$ while simultaneously incorporating the information from the variables:

$$
X=T P^{\prime}+E
$$

Two hundred spectral bands were integrated in the PLS analysis to identify a set of components that best 
estimated EW content. The RMSE (root mean square error) of the prediction was estimated with a leave-oneout cross-validation analysis (LOOCV) in a subset of the data with $66.7 \%$ of the observations. The EW content was predicted in the remaining $33 \%$ of the observations (validation set), integrating the optimum number of components detected in the PLSR model. The analysis was conducted with the plsr function included in the pls package in the statistical software $\mathrm{R}$ [73].

\section{Narrow and broad empirical spectral indices for the indirect estimation of the EW content of leaves}

Vegetation indices developed to phenotype the morphological and physiological characteristics of the plant (Tables 1 and 2) were calculated with the light reflectance. The correlation coefficients and the statistical significance of each of the VIs and the EW content were estimated with the cor function in the statistical software R.

Spectral indices were calculated by combining the light reflectance at different wavelengths. Eleven mathematical combinations of the spectral bands were calculated including the reflectance at every $3 \mathrm{~nm}$. The adjustment of the spectral resolution was done by averaging the percentage of light reflectance every 3 wavelengths. Additional combinations were also calculated with the average light reflectance of the spectral range of the blue, green, yellow, red and NIR regions (Table 2). In each of the mathematical combinations one, two and up to three bands were integrated. The significance of the linear models and the coefficient of determination $\left(\mathrm{R}^{2}\right)$ of every pairwise combination of the spectral bands was calculated with the $l m$ function in a leave one out cross-validation (LOOCV) analysis. The format of the linear models was the follow:

$$
y_{i}=\beta_{0}+\beta_{1}\left(x_{i}\right)
$$

where $y_{i}$ corresponds to the EW content $\left(\mathrm{mg} \cdot \mathrm{dm}^{-2}\right), x_{i}$ is the value of the spectral index, and $\beta_{0}$ and $\beta_{1}$ are the intercept and the slope of the model, respectively. A set of indices were selected based on the highest $R^{2}$ criteria in a LOOCV analysis. An inverse prediction approach was applied for assessing the predictive capability of the indices selected. These selected indices were fitted in a calibration data set (66\% of the observations) using the same format as in Eq 2 but with $y_{i}$ as the spectral index and $x_{i}$ the EW content $[74,75]$. The step after the models were fitted was to solve for $x_{i}$ with the estimates of the parameters calculated in the training data set with the follow equation: $X_{i}=\frac{y_{i}-\beta_{0}}{\beta_{i}}$. Estimates of the RMSE were bootstrapped 1000 times for each of indices and in the remaining $34 \%$ of the observations with the estimated values of EW with the equation and the chemically measured EW content.

\section{Stepwise regression (SWR)}

The spectral bands statistically associated with the EW content (Figs. 1 and 2) were incorporated to build a multivariate model for prediction. These variables were included and/or removed based on the significance of the partial F-values. The final models were selected when the inclusion of more spectral bands was statistically not justifiable. This analysis was conducted with the PROC REG statement in the statistical analysis software SAS [84] in a random training set of the total data ( $60 \%$ of the observations). The prediction models were selected based on the Mallows' Cp estimator. The estimate of the RMSE of each prediction model was calculated in the remaining $40 \%$ of the observations, and final models were choosen based on the lowest value of the RMSE.

\section{Plant material and field experimental trials for validation}

Two panels of spring wheat cultivars were evaluated during the agronomic cycle in 2013 at the Norman E. Borlaug Experimental Station (CENEB), Ciudad Obregon, Sonora in northwestern Mexico $\left(27.20^{\circ} \mathrm{N}, 109.54^{\circ} \mathrm{W}, 38\right.$ masl). The panels were two sets of 114 and 216 landraces and product of interspecific hybridization with wild relatives. These experimental trials were established as an alpha-lattice design with two replications in a raised bed system with two rows per bed and were planted 80 days later than the normal planting date of wheat in the Yaqui Valley. Late panting allowed the genotypes to be exposed to average daily temperatures of $28{ }^{\circ} \mathrm{C}$ and maximum environmental temperatures of $39{ }^{\circ} \mathrm{C}$ during the heading and anthesis stages of the crop. There was an intern row spacing within each bed of $10 \mathrm{~cm}(\mathrm{~cm})$, and a space between beds of $80 \mathrm{~cm}$. In 2016, an additional panel of synthetic derived wheat lines (SDLs) was also evaluated in Bushland and College Station, Texas under non-irrigated conditions. The panel of SDLs were established in an alpha-lattice design with two replications and a plot size of $3.0 \times 1.5 \mathrm{~m}$.

\section{Ground base radiometric measurements for the direct validation}

The canopy reflectance was collected with a FieldSpec $4 \mathrm{Hi}$-Res spectroradiometer that captured the light reflected in 2151 continuous bands with a spectral resolution of $3 \mathrm{~nm}(\mathrm{~nm})$ from 0.35 to $0.7 \mu \mathrm{m}$ and $8 \mathrm{~nm}$ from 1.4 to $2.1 \mu \mathrm{m}$. The measurements were collected from $11 \mathrm{AM}$ to $1 \mathrm{PM}$ by placing the optic fiber of the 
spectroradiometer $40 \mathrm{~cm}(\mathrm{~cm})$ above the canopy. The sensor was radiometrically calibrated with a white $\mathrm{BaSO} 4$ reference card for $100 \%$ reflectance and by blocking the light intercepted by the optic fiber for $0 \%$ reflectance. Ten readings per plot were captured and the average response of these signatures at a single wavelength was utilized in further analysis.

\section{Airborne hyperspectral information}

A set of aerial hyperspectral images were captured from the panel of wheat SDLs in College Station, Texas. The images were obtained with an Aisa KESTREL-10 hyperspectral camera, developed by SPECIM ${ }^{\circledR}$, and mounted on a Cessna 355 II aircraft. An altitude of 5000 feet $(\mathrm{ft})$ and a speed of $192 \mathrm{~km}$ per hour $(\mathrm{km} / \mathrm{h})$ were maintained through the flight of the aircraft. The camera captured 120 spectral bands with spectral and spatial resolutions of $5 \mathrm{~nm}$ and $0.25 \mathrm{~m}$, respectively. For calibration, four $8 \mathrm{~m}$ by $8 \mathrm{~m}$ ground tarps with nominal reflectance values of $8 \%, 16 \%, 32 \%$ and $48 \%$ were laid out in the field and captured in the hyperspectral images. The exact percentage of reflectance of the tarps was captured with a Hand-held 2 spectroradiometer. The range of this spectroradiometer is from 0.325 to $1.075 \mu \mathrm{m}$, and the spectral resolution is $3 \mathrm{~nm}$. The hyperspectral images were georeferenced and ensembled using the image analysis software ERDAS ${ }^{\circledR}$. Digital counts (DCs) were extracted individually for each tarp and for individual plots with the software ENVI ${ }^{\circledR}$. A linear regression model for a single spectral band was developed using light reflectance captured with the spectroradiometer from the tarps as the response variable (dependent) and the DCs as the independent variable. The linear equations were utilized for the estimation of the total canopy reflectance of each of the two hundred spectral bands in each plot.

\section{Efficiency of indirect selection of EW with spectral information}

The fourteen spectral indices (EWI) and the eleven regression models developed in this study (Table 4) were calculated with the ground based and aerial spectral information collected in the four experimental trials. Each of the indirect selection methods (spectral indices and models) was considered as an independent variable and subjected to an analysis of variance (ANOVA) for an alpha-lattice experimental design with the lmer function included in the package lme4 in the statistical software R. The variance components were extracted with the function varComp and estimates of the heritability in a broad sense $\left(\mathrm{h}^{2}\right)$ calculated according to the formula described by [85]: $\mathrm{h}^{2}=\frac{\sigma_{g}^{2}}{\sigma_{g}^{2}+\left(\sigma_{e}^{2} / r\right)}$ where $\sigma_{g}^{2}$ corresponds to the genetic variance, $\sigma_{e}^{2}$ to the error variance and $r$ is the number of replications in the experimental trial.

The statistical relationship of the target trait (phenotypic correlation) and the spectral method was calculated with the cor function of the stats package, while the genetic relationship of the traits (genotypic correlation) was estimated with the following equation: $\sigma_{\mathrm{g}}=\frac{\mathrm{COV}_{\mathrm{XY}}}{\sqrt{ } \operatorname{Var}_{\mathrm{X}} \mathrm{Var}_{\mathrm{y}}}$, where $\mathrm{COV}_{\mathrm{XY}}$ corresponds to the covariance estimate of the EWI and EW content calculated with the chemical method, $\operatorname{Var}_{x}$ is the variance of the EWI and $\operatorname{Var}_{\mathrm{y}}$ is the variance of EW [86]. The $\mathrm{COV}_{\mathrm{XY}}$ was calculated with the cov function, and $\operatorname{Var}_{\mathrm{x}}$ and $\operatorname{Var}_{\mathrm{y}}$ with the varComp function in R. The genetic correlation of the traits helps us to understand the pleiotropic action of the genes controlling the trait and its indirect selection.

The genetic gain (GG), the genetic advance (GA), the genetic advance with respect to the mean (GAM), the expected response to selection (R), the correlated response to selection (CR), the relative efficiency of indirect selection (RE) were all calculated according to Falconer [87]. GG, GAM, R, CR and RE were estimated as follows:

$\mathrm{GG}=\mathrm{h}^{2} *$ SDiff, where $\mathrm{h}^{2}$ is the estimate of the broad sense heritability of the trait, and SDiff is the selection differential of the trait (EW) with a selection pressure of $10 \%\left(\right.$ SDiff $\left.=\bar{x}_{\mathrm{p}}-\overline{\mathrm{x}}_{\mathrm{S}}\right)$.

$\mathrm{GA}=\mathrm{K}\left(\sigma_{\mathrm{p}}\right) \mathrm{h}^{2}$ where $\mathrm{K}$ is the selection differential, $\sigma_{p}$ is the phenotypic standard deviation of every spectral index or prediction model, and $h^{2}$ corresponds to the broad sense heritability. The $\mathrm{k}$ was estimated for $10 \%$ selection intensity as $\mathrm{k}=\overline{\mathrm{x}_{\mathrm{p}}}-\overline{\mathrm{x}_{\mathrm{s}}}$, where $\overline{\mathrm{x}_{\mathrm{p}}}$ and $\overline{\mathrm{x}_{\mathrm{s}}}$, are the population mean and the mean of the selected individuals, respectively.

$\operatorname{GAM}(\%)=\frac{\mathrm{GA}}{\overline{\mathrm{x}}} \times 100$, where $\overline{\mathrm{x}}$ is the grand mean of the specific character.

$\mathrm{R}=\mathrm{h}_{\mathrm{x}} \sigma_{\mathrm{x}}$, where $\mathrm{h}_{\mathrm{x}}$ is the square root of the heritability and $\sigma_{x}$ is the genotypic standard deviation.

$\mathrm{CR}=\mathrm{h}_{\mathrm{x}} \mathrm{r}_{\mathrm{gx}} \sigma_{\text {gy }}$, where $\mathrm{h}_{\mathrm{x}}$ is the square root of the heritability for trait $\mathrm{X}$ (spectral index), $\mathrm{r}_{\mathrm{gx}}$ is the genetic correlation of the spectral index and $\mathrm{EW}$, and $\sigma_{\mathrm{gy}}$ is the genotypic standard deviation of trait $\mathrm{Y}$ (EW).

$\mathrm{RE}=\frac{\mathrm{CR}}{\mathrm{R}}$, where $\mathrm{CR}$ is the correlated response to selection and $R$ is the expected response to selection for the trait.

\section{Abbreviations}

EW: Epicuticular wax; EWl: Epicuticular wax index; EWM: Epicuticular wax model; PT: Physiological traits; GY: Grain yield; LI: Light interception; RUE: Radiation use efficiency; WUE: Water use efficiency; CT: Canopy temperature; EWM: Epicuticular wax model; NIR: Near infrared radiation; GG: Genetic gain; RMSE: Root mean square error; CV: Coefficient of variation; CRD: Completely randomized design; PLSR: Partial least square regression; PCA: Principal component analysis; EWM: Epicuticular wax model; LOOCV: Leave-one-out crossvalidation; SWR: Stepwise regression; R: Response to selection; CR: Correlated 
response; RE: Relative efficiency of indirect selection; GA: Genetic advance; GAM: Genetic advance respect to the mean.

\section{Acknowledgements}

We thank Geraldine Opena for helping to set up the field trials in Texas and all the members of the Wheat Physiology Laboratory in CIMMYT Mexico for their support and assistance conducting the field trials in Mexico.

\section{Authors' contributions}

FCC, TDH and SM established the experimental trials and collected the data. MPR, MC and DBH advised FCC on the design of the experimental trials, writing and review of the manuscript. All authors read and approved the final manuscript.

\section{Funding}

This research project was fully funded by the International Maize and Wheat Improvement Center through the MASAGRO project.

\section{Availability of the data and materials}

The data sets generated and analyzed during the current study are available in the CIMMYT Publications Repository, https://data.cimmyt.org/dataset.xhtml? persistentld=hdl:11529/10548539. Correspondence should be addressed to camarillo.castillo.f@gmail.com.

\section{Declarations}

\section{Ethics approval and consent to participate}

Not applicable.

\section{Consent for publication}

All authors reviewed and approved the final version of the manuscript for submission.

\section{Competing interests}

The authors declare that they have no competing interests.

\section{Author details}

${ }^{1}$ Global Wheat Program, International Maize and Wheat Improvement Center (CIMMYT), Apdo. Postal 6-641, Mexico, D.F 06600, Mexico. ${ }^{2}$ USDA ARS, Dale Bumper National Rice Research Center, Stuttgart, AR 72160, USA. ${ }^{3}$ Agricultural Research Service, Center for Grain and Animal Health Research, USDA, 1515 College Ave., Manhattan, KS 66502, USA. ${ }^{4}$ Department of Soil and Crop Sciences, Texas A\&M University, College Station, Texas 77840, USA.

Received: 12 December 2020 Accepted: 26 May 2021

Published online: 07 June 2021

\section{References}

1. Awika JM. Major cereal grains production and use around the world. ACS Symp Ser. 2011;1089:1-13.

2. Braun HJ, Atlin G, Payne T. Multi-location testing as a tool to identify plant response to Global Climate Change. In: Reynolds MP, editor. Climate change and crop production. 2010. p. 115-38.

3. FAO. No Title [Internet]. 2018. http://www.fao.org/faostat/en/\#home

4. Godfray HCJ, Beddington JR, Crute IR, Haddad L, Lawrence D, Muir JF, et al. Food security: the challenge of feeding 9 billion people. Science. 2010;327:812-8.

5. Reynolds M, Foulkes J, Furbank R, Griffiths S, King J, Murchie E, et al. Achieving yield gains in wheat. Plant, Cell Environ. 2012;1-25.

6. Shewry PR. Wheat. J Exp Bot. 2009:60(6):1537-53.

7. Asseng S, Ewert F, Martre P, Rötter RP, Lobell DB, Cammarano D, et al. Rising temperatures reduce global wheat production. Nat Clim Chang. 2015;5(2):143-7

8. Cossani CM, Reynolds MP. Physiological traits for improving heat tolerance in wheat. Plant Physiol. 2012;160(4):1710-8.

9. Reynolds M, Manes Y, Izanloo A, Langridge P. Phenotyping approaches for physiological breeding and gene discovery in wheat. Ann Appl Biol. 2009;155(3):309-20.
10. Reynolds MP, Singh RP, Ibrahim A, Ageeb OAA, Quick IS. Evaluating physiological traits to complement empirical selection for wheat. In: Braun HJ, editor. Wheat: Prospects for Global Improvement. 1998. p. 143-52.

11. Reynolds MP, Saint Pierre C, Saad ASI, Vargas M, Condon AG. Evaluating potential genetic gains in wheat associated with stress-adaptive trait expression in elite genetic resources under drought and heat stress. Crop Sci. 2007;47:S172.

12. Reynolds MP, Trethowan RM. Physiological Interventions in Breeding for Adaptation to Abiotic Stress. In: Scale and Complexity in Plant Systems Research. 2007. p. 129-46.

13. Reynolds M, Langridge P. Physiological breeding. Curr Opin Plant Biol. 2016;31:162-71. https://doi.org/10.1016/j.pbi.2016.04.005.

14. Ebercon A, Blum A, Jordan WR. A rapid colorimetric method for epicuticuar wax content of sorghum leaves. Crop Sci. 1977;17:179-80.

15. Bi H, Kovalchuk N, Langridge P, Tricker PJ, Lopato S, Borisjuk N. The impact of drought on wheat leaf cuticle properties. BMC Plant Biol. 2017;17(1):1-14.

16. Müller C, Riederer M. Plant surface properties in chemical ecology. J Chem Ecol. 2005;31(11):2621-51.

17. Shepherd T, Griffiths DW. The effects of stress on plant cuticular waxes. New Phytol. 2006;171(3):469-99.

18. Samuels L, Kunst L, Jetter R. Sealing plant surfaces : cuticular wax formation by epidermal cells. Annu Rev Plant Biol. 2008;59:683-707.

19. Yeats TH, Rose JKC. The formation and function of plant cuticles. Plant Physiol. 2013;163(1):5-20.

20. Domínguez E, Heredia-Guerrero JA, Heredia A. The plant cuticle: old challenges, new perspectives. J Exp Bot. 2017;68(19):5251-5.

21. Borodich FM, Gorb EV, Gorb SN. Fracture behaviour of plant epicuticular wax crystals and its role in preventing insect attachment: A theoretical approach. Appl Phys A Mater Sci Process. 2010;100(1):63-71.

22. Kosma DK, Nemacheck JA, Jenks MA, Williams CE. Changes in properties of wheat leaf cuticle during interactions with Hessian fly. Plant J. 2010;63(1):31-43.

23. Raffaele $S$, Vailleau F, Léger A, Joubès J, Miersch O, Huard C, et al. A MYB transcription factor regulates very-long-chain fatty acid biosynthesis for activation of the hypersensitive cell death response in Arabidopsis. Plant Cell. 2008:20(3):752-67.

24. Premachandra GS, Hahn DT, Axtell JD, Joly RJ. Epicuticular wax load and water-use efficiency in bloomless and sparse-bloom mutants of Sorghum bicolor L. Environ Exp Bot. 1994;34(3):293-301.

25. Mondal S, Mason RE, Huggins T, Hays DB. QTL on wheat (Triticum aestivum L.) chromosomes $1 \mathrm{~B}, 3 \mathrm{D}$ and $5 \mathrm{~A}$ are associated with constitutive production of leaf cuticular wax and may contribute to lower leaf temperatures under heat stress. Euphytica. 2015;201(1):123-30.

26. Febrero A, Fernández S, Molina-Cano JL, Araus JL. Yield, carbon isotope discrimination, canopy reflectance and cuticular conductance of barley isolines of differing glaucousness. J Exp Bot. 1998;49(326):1575-81.

27. Richards R, Rawson H, Johnson D. Glaucousness in wheat: its development and effect on water-use efficiency, gas exchange and photosynthetic tissue temperatures. Funct Plant Biol. 1986;13(4):465.

28. Holmes MG, Keiller DR. Effects of pubescence and waxes on the reflectance of leaves in the ultraviolet and photosynthetic wavebands: A comparison of a range of species. Plant Cell Environ. 2002;25(1):85-93.

29. Baker NR, Rosenqvist E. Applications of chlorophyll fluorescence can improve crop production strategies: An examination of future possibilities. J Exp Bot. 2004;55(403):1607-21.

30. Grant RH, Jenks MA, Rich PJ, Peters PJ, Ashworth EN. Scattering of ultraviolet and photosynthetically active radiation by sorghum bicolor: influence of epicuticular wax. Agric For Meteorol. 1995;75(4):263-81.

31. Mulroy TW. Spectral properties of heavily glaucous and non-glaucous leaves of a succulent rosette-plant. Oecologia. 1979;38(3):349-57.

32. Ni Y, Xia R, Li J. Changes of epicuticular wax induced by enhanced UV-B radiation impact on gas exchange in Brassica napus. Acta Physiol Plant. 2014;36:2481-90

33. Javelle M, Vernoud V, Rogowsky PM, Ingram GC, The S, Phytologist N, et al Epidermis : the formation and functions of a fundamental plant tissue Linked references are available on JSTOR for this article : New mPP H Tansley review Epidermis : the formation and functions of a fundamental plant tissue. New Phytol. 2016. 189(1):17-39.

34. Robberecht R, Caldwell MM, Billings WD. Leaf ultraviolet optical properties along a latitudinal gradient in the Artic-Alphin life zone. Ecology. 2015:61(3):612-9. 
35. Gordon DC, Percy KE, Riding RT. Effect of enhanced UV-B radiation on adaxial leaf surface micromorphology and epicuticular wax biosynthesis of sugar maple. Chemosphere. 1998;36(4):853-8.

36. Caldwell MM, Robberecht R, Flint SD. Internal filters: Prospects for UVacclimation in higher plants. Physiol Plant. 1983;58(3):445-50.

37. Haghighattalab A, Pérez LG, Mondal S, Singh D, Schinstock D, Rutkoski J, et al. Application of unmanned aerial systems for high throughput phenotyping of large wheat breeding nurseries. Plant Methods. 2016;12:1-15.

38. Rebetzke GJ, Jimenez-Berni J, Fischer RA, Deery DM, Smith DJ. Review: High-throughput phenotyping to enhance the use of crop genetic resources. Plant. 2019;282:40-8. https://doi.org/10.1016/j.plantsci.2018.06. 017.

39. Sun J, Poland JA, Mondal S, Crossa J, Juliana P, Singh RP, et al. Highthroughput phenotyping platforms enhance genomic selection for wheat grain yield across populations and cycles in early stage. Theor Appl Genet. 2019;132(6):1705-20. https://doi.org/10.1007/ s00122-019-03309-0.

40. Juliana P, MontesinosLópez OA, Crossa J, Mondal S, González Pérez L, Poland J, et al. Integrating genomic-enabled prediction and highthroughput phenotyping in breeding for climate-resilient bread wheat. Theor Appl Genet. 2019;132(1):177-94. https://doi.org/10.1007/ s00122-018-3206-3.

41. Babar MA, Van Ginkel M, Klatt AR, Prasad B, Reynolds MP. The potential of using spectral reflectance indices to estimate yield in wheat grown under reduced irrigation. Euphytica. 2006;150(1-2):155-72.

42. Babar MA, Reynolds MP, Van Ginkel M, Klatt AR, Raun WR, Stone ML. Spectral reflectance to estimate genetic variation for in-season biomass, leaf chlorophyll, and canopy temperature in wheat. Crop Sci. 2006;46(3):1046-57.

43. Shakoor N, Lee S, Mockler TC. High throughput phenotyping to accelerate crop breeding and monitoring of diseases in the field. Curr Opin Plant Biol. 2017;38:184-92. https://doi.org/10.1016/j.pbi.2017.05.006.

44. Zhang C, Pumphrey MO, Zhou J, Zhang Q, Sankaran S. Development of an automated highthroughput phenotyping system for wheat evaluation in a controlled environment. Trans ASABE. 2019;62(1):61-74.

45. Montes JM, Melchinger AE, Reif JC. Novel throuhput phenotyping platforms in plant genetic studies. Trends Plant Sci. 2016;18(10):234. https:// doi.org/10.1002/central/CN-01266660/full.

46. Crain JL, Wei Y, Barker J, Thompson SM, Alderman PD, Reynolds M, et al. Development and deployment of a portable field phenotyping platform. Crop Sci. 2016;56(3):965-75.

47. Jordan CF. Derivation of leaf-area index from quality of light on the forest floor. Ecol Soc Am. 1969;50(4):663-6. http://www.jstor.org/stable/1936256

48. Rouse JW, Haas RH, Deering DW, Schell JA. Monitoring the vernal advancement and retrogradation (green wave effect) of natural vegetation. Greenbelt, Maryland; 1973.

49. Penuelas J, Filella I, Biel C, Serrano L, Save R. The reflectance at the 950-970 nm region as an indicator of plant water status. Int J Remote Sens. 1993;14(10):1887-905

50. Peñuelas J, Filella I, Gamon JA. Assessment of photosynthetic radiationuse efficiency with spectral reflectance. New Phytol. 1995;131(3):291-6.

51. Gamon JA, Serrano L, Surfus JS. The photochemical reflectance index: An optical indicator of photosynthetic radiation use efficiency across species, functional types, and nutrient levels. Oecologia. 1997;112(4):492-501.

52. Holman FH, Riche AB, Michalski A, Castle M, Wooster MJ, Hawkesford MJ. High throughput field phenotyping of wheat plant height and growth rate in field plot trials using UAV based remote sensing. Remote Sens. 2016;8(12):1031

53. Gong P, Pu R, Biging GS, Larrieu MR. Estimation of forest leaf area index using vegetation indices derived from Hyperion hyperspectral data. IEEE Trans Geosci Remote Sens. 2003:41((6 PART I)):1355-62.

54. Hassan MA, Yang M, Rasheed A, Yang G, Reynolds M, Xia X, et al. A rapid monitoring of NDVI across the wheat growth cycle for grain yield prediction using a multi-spectral UAV platform. Plant Sci. 2019;282:95-103. https://doi.org/10.1016/j.plantsci.2018.10.022.

55. Gitelson AA, Zur Y, Chivkunova OB, Merzlyak MN. Assessing carotenoid content in plant leaves with reflectance spectroscopy 9 . Photochem Photobiol. 2002;75(3):272
56. Blackburn GA. Quantifying chlorophylls and carotenoids at leaf and canopy scales: An evaluation of some hyperspectral approaches. Remote Sens Environ. 1998;66(3):273-85.

57. Gitelson AA, Merzlyak MN, Chivkunova OB. Optical properties and nondestructive estimation of anthocyanin content in plant leaves. Photochem Photobiol. 2001;74(1):38.

58. Peñuelas J, Frederic B, Filella I. Semi-empirical indices to assess carotenoids/chlorophyll-a ratio from leaf spectral reflectance. Photosynthetica. 1995;31(2):221-30

59. Rustioni L, Maghradze D, Failla O. Optical Properties of berry epicuticular waxes in four Georgian grape cultivars (Vitis vinifera L.). South African J Enol Vitic. 2012;33(2):138-43.

60. Mohammadian MA, Watling JR, Hill RS. The impact of epicuticular wax on gas-exchange and photoinhibition in Leucadendron lanigerum (Proteaceae). Acta Oecologica. 2007;31(1):93-101.

61. Robinson SA, Osmond CB. Internal gradients of chlorophyll and carotenoid pigments in relation to photoprotection in thick leaves of plants with crassulacean acid metabolism. Aust J Plant Physiol. 1994;21(4):497-506

62. Johnson DA, Richards RA, Turner NC. Yield, Water Relations, Gas Exchange, and Surface Reflectances of Near-Isogenic Wheat Lines Differing in Glaucousness 1. Crop Sci. 1983;23(2):318-25.

63. Barnes JD, Percy KE, Paul ND, Jones P, McLaughlin CK, Mullineaux $P M$, et al. The influence of UV-B radiation on the physicochemical nature of tobacco (Nicotiana tabacum L.) leaf surfaces. J Exp Bot. 1996;47(1):99-109.

64. Long ML, Patel HP, Cory CW, Stapleton EA. The maize epicuticular wax layer provides UV protection. Funct Plant Biol. 2003;2003(30):75-81.

65. Pfündel EE, Agati G, Cerovic ZG. Optical properties of the plant surfaces. In: Riedered M, Muller C, editors. Biology of the Plant Cuticle. Blackwell Publiching Ltd; 2007. p. 216-49.

66. Grant RH, Heisler GM, Gao W, Jenks M. Ultraviolet leaf reflectance of common urban trees and the prediction of reflectance from leaf surface characteristics. Agric For Meteorol. 2003;120:127-39.

67. Carvalho HDR, Heilman JL, McInnes KJ, Rooney WL, Lewis KL. Epicuticular wax and its effect on canopy temperature and water use of Sorghum. Agric For Meteorol. 2020. https://doi.org/10.1016/j.agrformet.2019.107893.

68. Filella I, Amaro T, Araus JL, Peñuelas J. Relationship between photosynthetic radiation-use efficiency of barley canopies and the photochemical reflectance index (PRI). Physiol Plant. 1996;96(2):211-6.

69. Peñuelas J, Gamon JA, Fredeen AL, Merino J, Field CB. Reflectance indices associated with physiological changes in nitrogen- and water-limited sunflower leaves. Remote Sens Environ. 1994;48(2):135-46.

70. Mohammed S, Huggins TD, Beecher F, Chick C, Sengodon P, Mondal S, et al. The role of leaf epicuticular wax in the adaptation of wheat (Triticum aestivum L.) to high temperatures and moisture deficit conditions. Crop Sci. 2018;58(2):679-89.

71. Tadesse W, Sanchez-Garcia M, Assefa SG. Genetic Gains in Wheat Breeding and Its Role in Feeding the World. Crop Breeding, Genet Genomics. 2019;1-28.

72. Crespo-Herrera LA, Crossa J, Huerta-Espino J, Autrique E, Mondal S, Velu $\mathrm{G}$, et al. Genetic yield gains in CIMMYT'S international elite spring wheat yield trials by modeling the genotype $x$ environment interaction. Crop Sci. 2017;57(2):789-801

73. Team RC. R: A language and environment for statistical computing [Internet]. Vienna, Austria: R Foundation for Statistical Computing; 2017. https://www.r-project.org/.

74. Lewis JR, Zhang A, Anderson-Cook CM. Comparing multiple statistical methods for inverse prediction in nuclear forensics applications. Chemom Intell Lab Syst. 2018;175:116-29. https://doi.org/10.1016/j. chemolab.2017.10.010.

75. Tanaka S, Kawamura K, Maki M, Muramoto Y, Yoshida K, Akiyama T. Spectral index for quantifying leaf area index of winter wheat by field hyperspectral measurements: A case study in Gifu Prefecture. Central Japan Remote Sens. 2015;7(5):5329-46.

76. Zarco-Tejada PJ, Berjón A, López-Lozano R, Miller JR, Martín P, Cachorro V, et al. Assessing vineyard condition with hyperspectral indices: Leaf and canopy reflectance simulation in a row-structured discontinuous canopy. Remote Sens Environ. 2005;99(3):271-87. 
77. Merzlyak MN, Gitelson AA, Chivkunova OB, Rakitin VY. Non-destructive optical detection of leaf senescence and fruit ripening. Physiol Plant. 1999;106(1):135-41.

78. Blackburn GA. Spectral indices for estimating photosynthetic pigment concentrations: A test using senescent tree leaves. Int J Remote Sens. 1998;19(4):657-75.

79. Gitelson AA, Kaufman YJ, Merzlyak MN. Use of a green channel in remote sensing of global vegetation from EOS- MODIS. Remote Sens Environ. 1996;58(3):289-98.

80. Chen JM. Evaluation of vegetation indices and a modified simple ratio for boreal applications. Can J Remote Sens. 1996;22(3):229-42.

81. Roujean $J$, Breon FM. Estimating PAR absorbed by vegetation from bidirectional reflectance measurements. Remote Sens Environ. 1995;51(3):375-84.

82. Gamon JA, Field CB, Bilger W, Bjorkman O, Fredeen AL, Panuelas J. Remote Sensing of the Xanthophyll Cycle and Chlorophyll Fluorescence in Sunflower Leaves and Canopies. Int Assoc Ecol [Internet]. 1990;85(1):17. http://www.jstor.org/stable/4219469
83. Tucker CJ. Red and photographic infrared linear combinations for monitoring vegetation. Remote Sens Environ. 1979;8(2):127-50.

84. Inc. SAS Institute. Base SAS (R) 9.3 Procedures Guide. Cary, NC: SAS Institute Inc; 2011.

85. Wayne Allard R. Principles of plant breeding. 1960

86. van Rheenen W, Peyrot WJ, Schork AJ, Lee SH, Wray NR. Genetic correlations of polygenic disease traits: from theory to practice. Nat Rev Genet. 2019;20(10):567-81. https://doi.org/10.1038/s41576-019-0137-z.

87. Falconer DS, Mackay TFC. Introduction to Quantitative Genetics (Fourth Edition). Vol. 12, Trends in Genetics. 1996. 464 p.

\section{Publisher's Note}

Springer Nature remains neutral with regard to jurisdictional claims in published maps and institutional affiliations.
Ready to submit your research? Choose BMC and benefit from:

- fast, convenient online submission

- thorough peer review by experienced researchers in your field

- rapid publication on acceptance

- support for research data, including large and complex data types

- gold Open Access which fosters wider collaboration and increased citations

- maximum visibility for your research: over 100M website views per year

At BMC, research is always in progress.

Learn more biomedcentral.com/submissions 